\title{
El profesional del Derecho en la formación del intérprete. Una experiencia didáctica
}

The expert in Law in the interpreting classroom. A didactic experience

\author{
Raquel Sanz-Moreno \\ Departamento de Teoría de los Lenguajes y Ciencias de la Comunicación \\ Universitat de València \\ Av. Blasco Ibáñez n³2, 46010, València \\ Raquel.Sanz-Moreno@uv.es
}

\begin{abstract}
Resumen
Este artículo presenta los resultados de una experiencia didáctica en el aula de interpretación en los servicios públicos que contó con la colaboración de dos expertos en Derecho Civil y Mercantil, por una parte, y Derecho de Extranjería por otra. Los alumnos del cuatro curso del Grado de Traducción y Mediación Interlingüística de francés de la Universitat de València participaron en varias sesiones de cuatro horas de interpretación de enlace con especialistas en la materia, que accedieron a colaborar en ejercicios de simulación en los que se planteaban distintos casos prácticos. Los alumnos participaron activamente adoptando el papel de intérpretes o de usuarios del servicio, y posteriormente contestaron a cuestionarios sobre las sesiones y los aspectos sobre deontología profesional que se habían abordado. La evaluación de las citadas encuestas demuestra que la interacción con el profesional cambió radicalmente la perspectiva del alumnado respecto a su consideración de la interpretación judicial: los alumnos acabaron otorgando más importancia a los factores extratextuales (sobre todo culturales) de la situación comunicativa, perdieron el miedo a hacer el ridículo o a hablar en público, desarrollaron estrategias de colaboración con el profesional y lo integraron como un elemento fundamental en la interpretación entendida como un trabajo en equipo. La socialización con el experto se presenta, pues, como una herramienta a explorar en el aula de interpretación.
\end{abstract}

Palabras clave: Interpretación en los servicios públicos, Interpretación judicial, Ejercicios de simulación, Socialización, Experiencia pedagógica.

\begin{abstract}
This article presents the results of a didactic experience in the classroom of public services interpreting, with the collaboration of two experts in Civil and Commercial Law, on the one hand, and Immigration Law, on the other. The students of the fourth year of the bachelor's degree in Translation and Cultural Mediation of the Universitat de València participated in several sessions of four hours each with specialists in law, who agreed to take part in roleplayings dealing with different real situations. The students participated actively in the sessions playing the roles of interpreters and of users of the service, and answered some questionnaires about the sessions and about professional ethics. The evaluation of the said questionnaires shows that the interaction with the legal professional completely changed the students' perspective towards legal interpreting: the students considered the importance of the extra textual elements (specially cultural) of the communicative situation, they lost the fear of ridicule, they developed collaboration strategies with the professional and integrated them as a key element of the interpretation understood as a co-operative work. Therefore, the socialization with the expert is presented as a useful tool to explore in the interpreting classroom.
\end{abstract}

Key words: Public services interpreting, Legal interpretation, Role playing, Socialization, Teaching experience. 


\section{Introducción}

Actualmente, el mercado laboral en España demanda cada vez más intérpretes con un alto nivel de formación y unos conocimientos muy especializados. El alumno no solo debe familiarizarse con las distintas modalidades de interpretación más demandadas (bilateral, consecutiva y simultánea) sino que además debe atender a la especialidad en cada caso (judicial, médica, comercial, etc.). Tal y como manifiesta Ruiz Mezcua (2015: 308), el profesor de interpretación tiene que lidiar con el miedo que tiene el estudiante, ya que se enfrenta, probablemente por primera vez en el grado de traducción, a una asignatura en la que predomina la oralidad, algo para lo que no ha recibido formación específica. Asimismo, el alumno debe desarrollar estrategias y adquirir numerosas destrezas (lingüísticas, temáticas y terminológicas, entre otras) en un espacio muy corto de tiempo.

El Espacio Europeo de Educación Superior (EEES), cuyo fin es la armonización de los sistemas universitarios europeos, conllevó la creación de los grados, cuya consecuencia directa fue el recorte de numerosas asignaturas que se impartían antiguamente en las licenciaturas. En el caso de la Facultad de Filología Traducción y Comunicación de la Universitat de València, el grado de Traducción y Mediación Interlingüística se implantó en el curso 2012-2013. Con anterioridad, en el segundo ciclo de la licenciatura en Traducción e Interpretación, se impartían 20 créditos de interpretación (simultánea y consecutiva) con la combinación de lenguas inglés - español. Con la llegada del grado, se redujeron los créditos de interpretación a 12 anuales (10 prácticos y 2 teóricos). No obstante, se añadieron dos combinaciones lingüísticas a la ya existente (francés - español y alemán - español). En el caso de las asignaturas semestrales Técnicas y Prácticas de Interpretación Francés-Español- Catalán (I y II), las clases se imparten una tarde a la semana, una hora teórica y tres prácticas. En el marco de esta asignatura, y durante el primer cuatrimestre, se llevó a cabo el proyecto que presentamos.

\section{Objetivos}

El objetivo esencial de este proyecto consistía en acercar al alumnado a la realidad de la práctica profesional real (Way, 2009). Dado que nuestro interés era proporcionar una formación adecuada a las necesidades y condiciones del mercado laboral actual, el alumnado debía conocer esa realidad de primera mano y tomar conciencia de las destrezas que debía desarrollar para poder desempeñar su función con éxito.

La formación por competencias en traducción no es una idea nueva, sino más bien al contrario. Desde Gile (1995) hasta el grupo PACTE (2001) o Kelly $(2002,2005)$, han sido numerosos los modelos que se han presentado sobre formación por competencias en traducción. En concreto, este proyecto perseguía la adquisición y el desarrollo de las siguientes subcompetencias descritas por Kelly (2005):

- Subcompetencia comunicativa en al menos dos lenguas y culturas: Los alumnos debían demostrar un perfecto dominio de la lengua materna (español) y de la lengua de trabajo (francés).

- Subcompetencia instrumental profesional: comprende aspectos básicos de la deontología profesional. Nuestra intención era tomar como base la práctica para introducir conceptos teóricos sobre códigos deontológicos aplicables en la interpretación en los servicios públicos (Valero Garcés, 2006; García-Beyaert, 2013).

- Subcompetencia psicofisiológica: comprende el "autoconcepto" o la conciencia de ser intérprete, la confianza en sí mismo, la capacidad de atención, de memoria, etc. A través de la socialización con el experto en Derecho, perseguíamos que el alumnado tomara conciencia de la importancia de su papel en la sociedad como garante de los derechos de los usuarios, y no como mero transmisor de un mensaje lingüístico. 
- Subcompetencia interpersonal: nuestro objetivo era que el alumnado desarrollara la capacidad para interrelacionarse y trabajar profesionalmente en equipo, en particular con el experto en Derecho, pero también con el resto de compañeros.

- Subcompetencia estratégica: desarrollo de estrategias diversas ante la resolución de problemas, adopción de decisiones y asunción y análisis de las consecuencias que se derivan de estas.

Si bien es cierto que la adquisición de determinadas destrezas descritas es difícil de evaluar (como la competencia psicofisiológica o interpersonal), nos servimos de un cuestionario que combinaba preguntas abiertas con preguntas en las que debía asignarse un puntaje (escala de Likert), para recabar las opiniones de los alumnos, lo que nos permitió desgranar los resultados que se presentan en este artículo.

\section{Ejercicios de simulación}

\subsection{Los ejercicios de simulación como herramienta pedagógica en el aula de interpretación}

Con el advenimiento del EEES, los papeles del profesor y del alumno se han visto modificados considerablemente. En este nuevo marco pedagógico, se fomenta el aprendizaje colaborativo (Barkley, Cross y Major, 2005) y el aprendizaje a lo largo de la vida. El profesor deja de ser una figura de autoridad, de fuente de todo conocimiento, y se convierte en orientador (López Noguero, 2007). En este contexto, los ejercicios de simulación se presentan como una de las herramientas didácticas más útiles en diversos ámbitos como en Derecho, en Psicología, en Pedagogía o en Medicina (Alonso 2009; Mitchell, 1998, Martín, 1992), así como en el ámbito de la interpretación de enlace (Fernández Pérez, 2015; Alonso y Baigorri, 2008; Martin, 2015).

Los ejercicios de simulación o role play presentan numerosas ventajas en el aula: permiten a los alumnos experimentar comportamientos en una situación cuasi real, pero sin los riesgos que esta conllevaría, así como identificar las distintas formas en que se puede reaccionar y evaluar el grado de eficacia de las soluciones aportadas. El alumno es consciente de las decisiones que adopta a lo largo de la dramatización y de las consecuencias que las mismas conllevan. Pero no todo son ventajas. El hecho de que el alumno deba asumir roles con los que no está en absoluto familiarizado puede entorpecer el role play; así, el alumno puede adoptar comportamientos estereotipados o, en el peor de los casos, negarse a participar porque no sabe cómo afrontar el papel que se le ha otorgado. En el caso de los ejercicios de simulación con trasfondo jurídico o judicial, los alumnos tienden a imitar comportamientos de jueces, fiscales o abogados que han visto en series de televisión o en cine estadounidenses que, no solo distan mucho de la realidad por ser dramatizaciones, sino sobre todo porque las situaciones tienen poco que ver con el derecho y el sistema jurisdiccional español. Por esa razón se pensó en integrar a un profesional de la materia en el aula de interpretación.

\subsection{La socialización con el profesional del Derecho}

Son muchos los autores que han señalado las múltiples ventajas que presenta la socialización del traductor con el experto en la materia (Kiraly, 2000; Monzó, 2003, 2006). La denominada socialización terciaria (Monzó, 2003) sería aquella que realiza el traductor o intérprete (en este caso) en relación a la comunidad receptora y que le lleva a conocer las condiciones reales en las que desempeña su trabajo. En este sentido, contar con un profesional del Derecho en el aula de interpretación fue altamente gratificante por diversos motivos:

- Mayor precisión: los juristas poseen una jerga propia de cuya dificultad y opacidad, en general, ni siquiera son conscientes, pero que se hace patente en su forma de comunicarse. Los expertos en Derecho hacen suyas las normas y convenciones propias de los géneros textuales con los que 
trabajan a diario y las emplean sin tomar en consideración el desconocimiento de las mismas por parte de los demás participantes en la situación comunicativa. Esto implica que el alumno escuchaba de primera mano cómo se expresaban los expertos y hacía un esfuerzo por interactuar con ellos, entenderlos e interpretarlos.

- Mayor realismo: en los ejercicios de simulación que planteamos, los casos prácticos provenían de experiencias propias del experto en Derecho, lo que contribuía a dar mayor realismo a las situaciones, ya que él mismo había sido sujeto activo en las mismas. Podía, por tanto, no solo indicar al alumnado cómo se había resuelto sino también cómo podría haberse mejorado la interacción.

- "Desmitificación" del profesional del Derecho: el hecho de que el abogado o asesor legal hubiera accedido a dedicar su tiempo al alumnado de forma desinteresada y gratuita ponía en valor su participación en el aula. Asimismo, la asimetría que se da en situaciones reales entre agentes del ámbito jurídico y el intérprete se diluyó notablemente, favoreciendo el desarrollo de estrategias de colaboración y trabajo en equipo con el profesional.

\section{Metodología}

Para el desarrollo de las sesiones de interpretación en servicios públicos se tuvo en cuenta el nivel de francés de los estudiantes (equivalente a un B2) así como su falta de familiaridad con la traducción jurídica, ya que en el grado se estudia la asignatura Traducción Especializada 3 que incluye diversos ámbitos de especialización (economía, política y administración general, etc.), pero que no permite tratar con profundidad terminología o fraseología jurídica.

El proyecto se articuló en cinco fases:

1. Encuesta previa: la finalidad consistía en determinar el grado de conocimiento que tenían los alumnos sobre cuestiones generales relacionadas con la interpretación en los servicios públicos. Se les pedía igualmente que evaluaran en una escala tipo Likert las cualidades del intérprete que creían más importantes a la hora de abordar ese tipo de interpretación, así como aquello que más les preocupaba antes de comenzarla. La valoración era de 0 a 5 puntos y se incluyeron una serie de destrezas basadas en el proyecto de código deontológico de García Beyaert (2013): competencia lingüística, conocimiento cultural, curiosidad, memoria, precisión terminológica, empatía, imparcialidad y secreto profesional y confidencialidad. El objetivo de estas preguntas era comprobar la idea que manejaban los alumnos sobre determinados entornos, tipos de clientes que iban a encontrarse etc., así como las dificultades a las que se enfrentaban.

2. Breve introducción teórica sobre la modalidad de interpretación así como al ámbito de especialidad. En esta fase, se les comunicaba dónde se iba a llevar a cabo la interpretación simulada (en una ONG, en un juzgado, en un despacho de abogados, en el Centro de Internamiento de Extranjeros (CIES), etc.) así como la rama de especialidad del profesional que iba a visitarnos (Derecho Civil, Mercantil, de Extranjería).

3. Ejercicio de simulación. En esta fase, se siguieron los pasos propuestos por Martín (1992):

- Motivación: con el objetivo de crear una atmósfera de confianza y participación (Mitchell, 1998: 5), se informó al alumnado de las múltiples ventajas que presenta el role play en el aula de interpretación. Asimismo, se les informó de que, para un posterior análisis, las sesiones se grabarían con cámara de vídeo. Para ello, se procedió, con carácter previo, al cambio de aula, ya que el laboratorio de idiomas no permitía la ubicación triangular tradicional que se da entre el intérprete, el profesional del Derecho y los usuarios. Se dispuso una mesa y varias sillas enfrente de la clase, de modo que todos los alumnos podían ver y escuchar con facilidad la interacción. La cámara se situó justo delante del profesional. Algunos de los alumnos manifestaron cierta 
incomodidad al respecto pero, dado que eran compañeros desde hacía cuatro años, la mayoría no planteó ningún problema. Además, se insistió en que las grabaciones solo se utilizarían para fines de investigación y de docencia, ya que sería más fácil detectar determinados errores mediante la imagen. Y si bien al principio fue un poco más complicado dar con voluntarios, al final no hacía falta animarles, ya que manifestaron un creciente interés por participar activamente en la sesión. Al finalizar, la mayoría de los alumnos que habían participado como intérpretes y actores confesaron que se habían olvidado de la presencia de la cámara.

Por otra parte, también se enfatizó el papel de aquellos alumnos que no participaban en el role play como observadores privilegiados, y se les animó a tomar notas y a apuntar todas las dudas que les surgían con el fin de debatirlas al final.

- Preparación para la dramatización: Se realizó una breve presentación del profesional del Derecho, haciendo hincapié en su experiencia laboral con intérpretes en los distintos ámbitos. A continuación, se solicitaron voluntarios para participar en la simulación. Se entregaron tarjetas en las que figuraba el papel que tenía que desempeñar el actor-usuario de servicios en una ONG o en un despacho de abogados. En otra tarjeta se describía brevemente el papel del profesional del Derecho, al que previamente se había puesto al corriente de los casos (Ver Figuras 1 y 2). Estos provenían tanto de la experiencia laboral del profesional y la profesora (intérprete y abogada) como, en menor medida, de los casos prácticos descritos por Láraro (2007) y Jiménez Ivars (2012). El intérprete debía realizar una interpretación de enlace, pero no se le proporcionaba ningún tipo de instrucción.

\section{Caso práctico 1- Ficha para el trabajador en ONG}

Una mujer africana se presenta en la ONG porque quiere solicitar asilo político. Es homosexual y en su país se le ha perseguido por ese motivo. Sin embargo, a ella le da vergüenza decirlo.

$\rightarrow$ Intenta ganarte la confianza de la chica para que pueda hablar con libertad de lo que le ocurre.

Figura 1: Papel del trabajador de la ONG. Ejemplo

\section{Caso práctico 1- Ficha para el usuario}

Eres una mujer africana que te diriges a una $\mathrm{ONG}$ porque quieres solicitar asilo político en España. Eres homosexual y en tu país te persiguen por este motivo. Quieres información sobre la solicitud de asilo pero te da vergüenza revelar tu condición sexual.

$\rightarrow$ No debes desvelar el motivo de la solicitud de asilo, a no ser que el trabajador de la ONG te inspire suficiente confianza para desvelarle un hecho tan íntimo.

Figura 2: Papel del usuario. Ejemplo

- Dramatización: El alumno-actor y el jurista desempeñaban su papel, mientras que el intérprete llevaba a cabo una interpretación de enlace (francés- español- francés). El hecho de contar con un experto en Derecho facilitaba también la tarea del alumno-actor, ya que normalmente el primero 
tomaba la iniciativa, interactuaba con él con normalidad, y desbloqueaba la situación cuando era necesario.

- Debate: Una vez concluida la interacción, se iniciaba un turno de debate y preguntas. Los alumnos "observadores" planteaban distintas estrategias de las adoptadas por los participantes en la interacción o apoyaban las que se habían llevado a cabo. La profesora les interpelaba con preguntas constantes sobre qué hubieran hecho ellos o qué les parecía la estrategia que se había adoptado ante tal situación. El jurista tomaba la palabra al final, para explicar lo que habitualmente sucede en esos casos y contrastar lo que se había producido en la simulación con la experiencia profesional real.

4. Encuesta posterior: Se le pidió al estudiantado que volviese a considerar las destrezas necesarias para la realización de ese tipo de interpretación así como aquello que más les había preocupado a lo largo de la sesión. Asimismo, se les pidió que valoraran la sesión y al ponente.

\section{Resultados}

\subsection{Interpretación en ONG. Interacción con el experto en Derecho de extranjería}

La sesión de interpretación en el ámbito de las ONG contó con Papa Diegane, intérprete en ONG y en el CIES de Valencia, y especialista en Derecho de extranjería (Máster Universitario Internacional en Migraciones de la Universitat de València). La clase estaba compuesta por 19 alumnos y 9 de ellos participaron activamente en los ejercicios de simulación, ya sea como actores (5) o como intérpretes (4). Cada intérprete realizó un ejercicio de simulación completo que solo se realizaba en una ocasión. Al principio de cada interacción, se dejaba unos minutos para que el intérprete hablara con el especialista en Derecho de extranjería, y se pusieran de acuerdo en los turnos de palabra.

Con carácter previo, se formularon una serie de preguntas generales. Entre ellas, destacamos que aunque la mayoría de alumnos manifestaron que no habían realizado interpretación en este ámbito, 4 de ellos se sentían preparados para abordarla. Las razones que adujeron fueron que tenían "un buen nivel de francés y curiosidad" (1), "que era "extrovertido" (1), que "este tipo de interpretación no conlleva gran dificultad" (1) y que tenían "fluidez verbal" (1). Por otra parte, se observó cierta confusión en cuanto a los usuarios que los alumnos creían encontrar en una ONG: "Muy variados, entre ellos, inmigrantes", "Personas que necesitan ayuda de algún tipo", "Inmigrantes que necesiten ayuda de tipo sanitario o que no tengan un lugar donde vivir", "Personas honestas y humildes" etc. Como se puede apreciar, los estereotipos jugaron un papel muy importante antes de abordar la interpretación, ya que el perfil de usuario que tenían en mente los alumnos era esencialmente de personas inmigrantes, pobres y sin formación, lo cual, en ocasiones, no se corresponde con la realidad. También nos parece interesante traer a colación que, aunque la mayoría de alumnos sabía a qué correspondían las siglas ONG (organización no gubernamental), lo cierto es que eran incapaces de facilitar una definición de la misma y describir sus funciones, aunque dos de ellos se sirvieron de ejemplos para hacerlo (Médecins sans frontières y Valencia Acoge).

En cuanto a las cualidades del intérprete, antes de iniciar la sesión (ver Tabla 1), los alumnos pensaban que el conocimiento cultural era la cualidad más importante que debía reunir un intérprete $(4,68 / 5)$ seguido de la confidencialidad y el secreto profesional $(4,63 / 5)$. A continuación, los alumnos situaban la memoria y la imparcialidad al mismo nivel $(4,57 / 5)$, mientras que la precisión terminológica les parecía lo menos importante (3,73/5). Esto último puede explicarse por el concepto que los alumnos manejaban tanto de lo que era una ONG como del perfil de usuario que creían que iban a encontrar, ya que consideraban que eran personas provenientes de entornos culturales muy distintos y la mayoría sin formación. Por eso, la mayoría de los alumnos manifestaron que preferían sacrificar la precisión terminológica en aras a una comprensión general del usuario. 
Del análisis de las encuestas posteriores a la sesión se desprende que los alumnos otorgaron aún más importancia al conocimiento cultural $(4,89 / 5)$ y la empatía $(4,26 / 5)$. No obstante, se observa un claro descenso en la valoración de la imparcialidad $(4,05 / 5)$ y la competencia lingüística $(3,13 / 5)$. En cuanto a la imparcialidad, es probable que los resultados deriven del posterior debate que se planteó sobre la mayor o menor implicación del intérprete en la interacción. La profesora introdujo la explicación teórica sobre "el modelo abogacía" y "el modelo imparcial" descritos por Cambridge (2003: 110-123) y planteó a los alumnos que reflexionaran sobre los límites (si los hubiera) de la imparcialidad en la interpretación en una ONG. La mayoría de alumnos, después de escuchar y debatir con el experto, concluyeron que en este tipo de interpretación, la implicación personal y emocional formaba parte intrínseca de la misma, por lo que no solo era difícil ser imparcial sino que era aconsejable cierto posicionamiento por parte del intérprete. A pesar de que los alumnos abogaban por la visibilidad y el posicionamiento del intérprete, pidiendo aclaraciones, realizando preguntas propias e interpelando directamente al profesional, se les hizo notar igualmente que el "modelo abogacía" (que parecían adoptar sin saberlo) contradecía no solo numerosos códigos éticos de asociaciones de intérpretes (IMIA, NAJIT, etc.) sino también gran parte de la literatura sobre interpretación en los servicios públicos, lo que alimentó un interesante debate sobre los límites de la imparcialidad del intérprete en este ámbito.

\begin{tabular}{lcc}
\hline $\begin{array}{c}\text { Cualidades interpretativas } \\
\text { (sobre 5) }\end{array}$ & $\begin{array}{c}\text { Antes de la } \\
\text { interacción con } \\
\text { el profesional }\end{array}$ & $\begin{array}{c}\text { Después de la } \\
\text { interacción con el } \\
\text { profesional }\end{array}$ \\
\hline Competencia lingüística & 4,21 & 3,13 \\
Conocimiento cultural & 4,68 & 4,89 \\
Curiosidad & 4,42 & 4,47 \\
Memoria & 4,57 & 4,21 \\
Precisión terminológica & 3,73 & 3,63 \\
Empatía & 4,1 & 4,26 \\
Imparcialidad & 4,57 & 4,05 \\
Secreto profesional & 4,63 & 4,52 \\
\hline
\end{tabular}

Tabla 1: Valoración de las cualidades del intérprete en ONG

En cuanto a la competencia lingüística, es probable que el resultado responda a la propia experiencia del estudiantado, que era muy consciente del nivel de francés que tenía y de sus limitaciones antes de la sesión.

\begin{tabular}{lcc}
\hline \multicolumn{1}{c}{$\begin{array}{c}\text { Dificultades } \\
\text { (sobre 5) }\end{array}$} & $\begin{array}{c}\text { Antes de la } \\
\text { interacción con } \\
\text { el profesional }\end{array}$ & $\begin{array}{c}\text { Después de la } \\
\text { interacción con el } \\
\text { profesional }\end{array}$ \\
\hline Quedarse en blanco & 3,57 & 2,47 \\
Hacer el ridículo & 2,47 & 1,26 \\
Que no se me entienda & 3,31 & 3,05 \\
No entender & 3,68 & 2,84 \\
Afectación psicológica & 1,5 & 2,1 \\
No encontrar la palabra adecuada & 3,1 & 3 \\
No saber reaccionar frente a imprevistos & 3,57 & 3,63 \\
No ser imparcial & 2,21 & 2,73 \\
\hline
\end{tabular}

Tabla 2: Valoración de las dificultades a la hora de abordar la interpretación de enlace en ONG

Entre las preocupaciones que tenían los alumnos antes de comenzar la interacción (ver Tabla 2), destacamos el miedo a hacer el ridículo $(2,47 / 5)$ o a quedarse en blanco $(3,57 / 5)$, algo que muchos alumnos manifiestan en clase de interpretación dado el estrés que les produce esta actividad. Sin embargo, una vez finalizada la sesión, parece que los alumnos no otorgaban tanta importancia a estas dos cuestiones $(1,26 / 5$ : hacer el ridículo; 2,47/5: quedarse en blanco). No obstante, otras cuestiones les seguían causando 
preocupación, como no ser imparcial $(2,73 / 5)$ o que les pudiera afectar psicológicamente lo vivido en la ONG $(2,1 / 5)$. Parece, pues, que el contacto con el profesional de la ONG, que contó experiencias duras con determinados usuarios, en particular en el CIES, hizo que los alumnos se plantearan el eventual impacto emocional y psicológico que se pudiera derivar de la interpretación en los servicios públicos a largo plazo (Valero, 2006), algo que no se habían cuestionado de la misma forma antes de iniciar la sesión.

En resumen, la sesión les infundió confianza en ellos mismos y les animó a desarrollar distintas estrategias ante los imprevistos que podían surgir o superar las dificultades que tenían con la lengua francesa. En general, tanto el ponente como la sesión fueron valorados muy positivamente $(9,7 / 10)$ y 17 de los 19 alumnos manifestaron que su perspectiva sobre la interpretación en ONG había cambiado después de la sesión con el profesional. Entre las valoraciones globales del estudiantado sobre el conjunto de la sesión destacamos:

"Antes de esta clase pensaba que la intérprete era una profesional sentada en una silla traduciendo literalmente. Me he dado cuenta que es más importante el sentido, tener contacto y mantener una confianza con el cliente para facilitar la comunicación y la comprensión".

"Mi opinión era buena, ahora me resulta más interesante y, a pesar de no sentirme preparada, la sesión me ha animado a continuar descubriendo este tipo de interpretación y a hacer alguna".

"Yo me he agobiado al no encontrar el término exacto y me he dado cuenta de que no siempre es necesario. Me he quedado con ganas de interpretar. Me encantaría repetir para poder comprobar por mí misma que puedo hacerlo".

La interacción con un experto en Derecho de extranjería que, además, ejerce habitualmente como intérprete en el CIES de Valencia, contribuyó a que el alumno desarrollara estrategias de colaboración con él, preguntándole dudas y solicitando aclaraciones. Asimismo, el alumnado aprendió a cuestionar sus propias decisiones, reflexionando sobre las eventuales consecuencias que podían tener en la vida real. Pero además, la socialización le infundió confianza y contribuyó a afirmar su rol esencial en el proceso interpretativo.

\subsection{Interpretación en despacho de abogados. Interacción con el experto en Derecho Civil y Mercantil}

La sesión de interpretación en el ámbito jurídico contó con la letrada especialista en Derecho Civil y Mercantil Beatriz Edo Alfonso, colegiada n 11806 del Ilustre Colegio de Abogados de Valencia. En este caso, participaron 17 alumnos en las encuestas y 10 de ellos participaron activamente en el role play, ya sea como actores o como intérpretes ( 5 actores y 5 intérpretes).

De nuevo, con carácter previo, se formularon una serie de preguntas generales. Destacamos que 15 alumnos manifestaron que no se sentían preparados para abordar este tipo de interpretación. La falta de conocimiento de terminología especializada fue la causa más aducida (9), seguida de la falta de formación en general (3). Los alumnos que, sin embargo, se consideraban listos para realizar una interpretación judicial manifestaron que "hay que lanzarse a todo tipo de experiencia" (1) o también que "tengo un buen nivel de francés y curiosidad por aprender" (1). Pero lo cierto es que las respuestas a las preguntas generales dejaron entrever un gran desconocimiento del mundo del Derecho en general. Así, ante la pregunta "¿Qué es un juzgado?" nos encontramos respuestas como: "un edificio donde se dictan acusaciones y sentencias", "lugar donde se acusa o se defiende a alguien", "lugar donde se llevan a cabo los juicios", o "tribunal en el que el juez es la autoridad y es el encargado de resolver ciertos casos". Por otra parte, ante la pregunta "¿Cuál es la diferencia entre la jurisdicción civil y penal?”, 13 de los 17 alumnos dejaron la respuesta en blanco. Uno de ellos manifestó que "en penal puedes ir a la cárcel y hay sanciones"; otras respuestas fueron "el penal suena peor", que "en la jurisdicción penal las penas son mayores" o que "la civil se resuelve económicamente y la penal con prisión". Ante estas respuestas, y 
constatando el profundo desconocimiento sobre el mundo judicial en general, se tramitó una visita guiada a la Ciudad de la Justicia de Valencia para que los alumnos conocieran de primera mano el entorno en el que se movía habitualmente un intérprete judicial y se familiarizaran con aspectos generales del Derecho.

Antes de comenzar la sesión (Tabla 3), los alumnos valoraron la precisión terminológica, la imparcialidad y el secreto profesional como las cualidades más importantes ante una interpretación jurídica $(4,88 / 5)$ mientras que la empatía fue la cualidad menos valorada $(3,76 / 5)$. Destacamos que, menos esta última, todas las cualidades que se propusieron a los alumnos para su valoración superaron los 4 puntos sobre 5, por lo que se otorgó una gran importancia a todas ellas. Los alumnos manifestaron que la interpretación jurídica y judicial era de las especialidades más serias y difíciles que se habían abordado en clase (por encima de la sanitaria, la comercial o la social en ONG), por lo que consideraban que debían dominarse todas las destrezas. En este caso, entendían que el intérprete sí debía ser un profesional de la interpretación (a diferencia de la ONG) y además debía reunir una formación específica, no solo en cuanto a terminología (7 de los 17 alumnos) sino también conocimientos de Derecho ( 7 de los 17 alumnos). Se observa además que la interacción con la abogada no modificó sustancialmente las valoraciones de las cualidades. La empatía seguía siendo la menos valorada $(3,33 / 5)$ mientras que la precisión terminológica $(4,75 / 5)$ y el secreto profesional $(4,33 / 5)$ seguían siendo de las más valoradas. Es probable que estas valoraciones vengan condicionadas por el debate que se suscitó después de la interacción y que llevó a la profesional del Derecho a explicar en qué consistía el secreto profesional y la confidencialidad entre abogado y cliente y su extensión a la intervención del intérprete en el contexto de la interpretación jurídica y judicial. Varios alumnos expresaron su sorpresa al entender que no se predicaba la misma obligación de confidencialidad de un abogado o de un intérprete, y aducían a la ausencia de un código deontológico del intérprete, lo que permitió introducir conceptos teóricos sobre códigos deontológicos en interpretación e ilustrar a los alumnos con algunos ejemplos prácticos (Lázaro, 2007; Jiménez Ivars, 2012).

Por otra parte, también esto explicaría el que el alumno rechazara la empatía como cualidad del intérprete en este tipo de interpretación, ya que la abogada explicó el tipo de clientes con los que se pueden tratar en este ámbito (y más concretamente en el penal) y las obligaciones a las que se somete el intérprete, como el respeto a la presunción de inocencia. La mayoría de los alumnos consideró muy difícil tratar con personas acusadas de delitos y 13 de los 17 alumnos manifestaron que rechazarían el encargo de interpretación de una persona acusada de un delito grave contra las personas porque se veían incapaces de ser imparciales. En ese sentido, los alumnos insistieron en la necesidad de formación especializada en el ámbito de la interpretación judicial, en la que se abordara el aprendizaje de la imparcialidad, su contenido y sus límites. A nuestro juicio, esta reflexión también es un resultado positivo, ya que da cuenta de la asunción de responsabilidad por parte del alumnado y toma de conciencia de la importancia de la profesionalidad del intérprete en este contexto.

\begin{tabular}{lcc}
\hline $\begin{array}{c}\text { Cualidades interpretativas } \\
\text { (sobre 5) }\end{array}$ & $\begin{array}{c}\text { Antes de la } \\
\text { interacción con el } \\
\text { profesional }\end{array}$ & $\begin{array}{c}\text { Después de la } \\
\text { interacción con el } \\
\text { profesional }\end{array}$ \\
\hline Competencia lingüística & 4,58 & 4,5 \\
Conocimiento cultural & 4,05 & 3,66 \\
Curiosidad & 4 & 3,66 \\
Memoria & 4,7 & 4,25 \\
Precisión terminológica & 4,88 & 4,75 \\
Empatía & 3,76 & 3,33 \\
Imparcialidad & 4,88 & 4 \\
Secreto profesional & 4,88 & 4,33 \\
\hline
\end{tabular}

Tabla 3: Valoración de las cualidades del intérprete en despacho de abogados

Se observa que una vez finalizada la sesión (Tabla 4), el alumno parece perder el miedo a no encontrar la palabra adecuada $(3,84 / 5)$ o a no comprender lo que expresa el profesional $(3,08 / 5)$ y manifiesta que podría 
desarrollar diversas estrategias desde "preguntarle el significado de algún término que desconozco" (5 alumnos), "pedirle que repita" (7 alumnos) o "que lo explique en otras palabras" ( 2 alumnos). El miedo a quedarse en blanco o a hacer el ridículo también se reduce considerablemente (pasando de 3,41/5 y de 2,11/5 antes de la sesión, a 2,66/5 y 1,33/5 después), en este caso aún más, ya que se trataba de la segunda sesión y los alumnos habían adquirido más seguridad y confianza en ellos mismos, al mismo tiempo que se había creado una dinámica de grupo fantástica en la que todos colaboraban y participaban activamente en todas las clases.

Por otra parte, destacamos que la diferencia de estatus respecto al abogado tampoco figuraba entre una de las preocupaciones mayores antes de la sesión $(1,58 / 5)$ pero se redujo drásticamente después de la socialización con la jurista $(0,98 / 5)$. Esto obedece esencialmente a que la abogada contribuyó a tranquilizar a los alumnos, dar cuantas explicaciones requerían, responder a todas las dudas e incluso llegar a repetir hasta en tres ocasiones la explicación de un concepto porque el alumno no acababa de entender su significado. En definitiva, su predisposición y ayuda expresa facilitó el que el alumnado la percibiera como una parte fundamental en el desarrollo de su trabajo.

\begin{tabular}{lcc}
\hline \multicolumn{1}{c}{$\begin{array}{c}\text { Dificultades } \\
\text { (sobre 5) }\end{array}$} & $\begin{array}{c}\text { Antes de la } \\
\text { interacción con } \\
\text { el profesional }\end{array}$ & $\begin{array}{c}\text { Después de la } \\
\text { interacción con el } \\
\text { profesional }\end{array}$ \\
\hline Quedarse en blanco & 3,41 & 2,66 \\
Hacer el ridículo & 2,11 & 1,33 \\
Que no se me entienda & 3,17 & 3,08 \\
No entender & 4,05 & 3,08 \\
Afectación psicológica & 1,47 & 1,25 \\
No encontrar la palabra adecuada & 4,58 & 3,84 \\
No saber reaccionar frente a imprevistos & 3,52 & 3,5 \\
No ser imparcial & 2,52 & 2,58 \\
Diferencia de estatus & 1,58 & 0,98 \\
\hline
\end{tabular}

Tabla 4: Valoración de las dificultades a la hora de abordar la interpretación de enlace en despacho de abogados

La valoración global tanto de la sesión como de la ponente alcanzó un 9,5/10 y los alumnos manifestaron igualmente una gran satisfacción respecto a la misma; no obstante, al finalizar la sesión, los 17 alumnos indicaron que requerían de formación más específica y continua para esta especialidad. En este sentido, comentaron que la interacción con profesionales del Derecho podía constituir una herramienta útil en la formación de futuros intérpretes en servicios públicos.

\section{Valoración global del proyecto}

Todos los estudiantes que habían participado en las sesiones manifestaron que su percepción respecto a la interpretación en los servicios públicos había cambiado gracias a la interacción con un profesional del Derecho en el aula.

Tras realizar los ejercicios de simulación, el alumnado se consideraba competente para ejercer de intérprete a pesar de no contar ni tan siquiera con conocimientos lingüísticos sólidos, y se sentían más confiados a la hora de desarrollar otro tipo de estrategias ("Pedirle que repita, espere o explique lo que quiere decir"). Además, muchos de ellos indicaron su interés en continuar formándose en este ámbito. Otra de las ventajas enunciada por los alumnos es que pudieron analizar las decisiones que habían tomado, lo que les ayudaba a abordar situaciones similares en un contexto parecido. En ese sentido, los alumnos resumieron las ventajas que percibían a la hora de contar con un profesional del Derecho en el aula de interpretación: mayor realismo y autenticidad. El profesional les relataba su experiencia, de primera mano, y dado el clima de 
confianza que se había generado en la clase, fomentado por la formulación de preguntas y la participación activa del jurista en los debates, los alumnos no cuestionaban lo que se les relataba. Además, les daba más seguridad saber que el abogado o asesor había experimentado en primera persona esa situación. Tal y como manifestó un alumno: "Un profesional siempre puede darte consejos muy útiles sobre cómo reaccionar ante determinadas situaciones. También te sirve de apoyo o de cómplice a la hora de establecer la comunicación, ya que puedes consultarle dudas y te puede ayudar a transmitir un mensaje difícil de entender de manera fácil porque se da cuenta cuando no entiendes algo...”.

Otra de las ventajas que presenta el role play con profesionales es la eliminación de prejuicios y la (auto)evaluación de las decisiones aportadas en cada caso. Asimismo, muchos alumnos entendieron que la función del intérprete no es la de ser un mero transmisor de un mensaje, sino que, al contrario, desempeña un amplio abanico de tareas que necesitan del desarrollo de numerosas destrezas y habilidades que, según sus palabras, parecen más fáciles de adquirir y perfeccionar cuando se trabaja con un experto en Derecho. Los alumnos valoraron positivamente la presencia del jurista en el aula, ya que había supuesto un primer contacto directo con la realidad de la interpretación en los servicios públicos así como, en algunos casos, la primera vez que interactuaban con abogados o especialistas en Derecho. El 63\% de los alumnos manifestaron que habían "desmitificado" la figura del abogado, entendiéndola como alguien más cercano y receptivo a las dudas y preguntas que podía formular el intérprete. Además, 7 de los 9 alumnos que hicieron el papel de intérprete en ambas sesiones expresaron que habían sentido que podían trabajar con el profesional en un marco de trabajo colaborativo, y no habían percibido la asimetría que se puede dar entre profesional del Derecho e intérprete.

\section{Conclusión}

Este proyecto ha supuesto una experiencia didáctica y personal muy enriquecedora para todos sus integrantes: los alumnos han tenido el privilegio de contar con la generosidad, la experiencia, el saber y la participación activa de expertos en Derecho que tratan a diario con intérpretes en contextos reales. La profesora ha podido adoptar el papel de guía y observadora privilegiada, introduciendo conceptos teóricos sobre la base de la práctica, animando a la participación del alumnado y evaluando la interacción desde un punto de vista más técnico. El ofrecer clases más innovadoras es siempre un riesgo pero los resultados han sido más que satisfactorios. El profesional tomaba conciencia, a veces por primera vez, de lo difícil que era el papel del intérprete en determinados contextos; disfrutaba al entrar en contacto con los que iban a ser sus futuros compañeros de trabajo y explicaba su experiencia con la precisión y la reflexión pausada que ofrece la distancia y la práctica. Sería, sin embargo, deseable, que este tipo de iniciativas contaran con los recursos materiales y económicos adecuados para poder gratificar y agradecer la participación de expertos en Derecho en nuestras aulas y contribuir así a una formación de calidad más cercana a la realidad de la sociedad que nuestros alumnos van a encontrarse al integrarse en el mercado laboral.

\section{Referencias}

Alonso, I., y Baigorri, J. (2008) Enseñar la interpretación en los servicios públicos: una experiencia docente. Redit, 1, pp. 1-25.

Alonso Rimo, A. (2009) Aprendizaje cooperativo en Derecho penal: algunas estrategias. En: García Añón J. (Ed.), Miradas a la innovación: experiencias de innovación en la docencia del Derecho. Universidad de Valencia, Valencia.

Barkley, E.F., Cross, P., y Major, C.H. (2005) Técnicas de aprendizaje colaborativo. Manual para el profesorado universitario. Ediciones Morata, S.L., Madrid.

Cambridge, J. (2003) Unas ideas sobre la interpretación en los Centros de Salud. En: Valero Garcés, C. (Ed.), Traducción e Interpretación en los servicios públicos. Contextualización, actualidad y futuro, (pp. 51-69). 
Comares, Granada.

Fernández Pérez, M. (2015) Designing role-play Models for Telephone Interpreting Training. MonTI. Monografias de Traducción e Interpretación, núm. esp. 2, pp. 259-279. doi: http://dx.doi.org/10.6035/MonTI.2015.ne2.10

García Beyaert, S. (2013) Código deontológico. Principios éticos y pautas de buenas prácticas para la interpretación en los servicios públicos y el ámbito comunitario. Recuperado de http://www.l-ink.org/Codigo_deontologico_ISPC.pdf (última consulta: 7 de abril de 2017)

Gile, D. (1995) Basic Concepts and Models for Interpreter and Translator Training. John Benjamins, Ámsterdam.

Jiménez Ivars, A. (2012) Primeros pasos hacia la interpretación. Inglés-Español:: Servicio de Comunicación y Publicaciones. Universitat Jaume I, Castellón.

Kelly, D. (2002) Un modelo de competencia traductora: bases para el diseño curricular. Puentes: Hacia nuevas investigaciones en la mediación intercultural, 1, pp. 9-20.

Kelly, D. (2005) A Handbook for Translator Trainers. Translation Practices Explained. St. Jerome, Manchester.

Kiraly, D. (2000) A Social Constructivist Approach to Translator Education. Empowerment from Theory to Practice. St. Jerome, Manchester.

Lázaro, R. (2007) Dilemas éticos del traductor/intérprete en los servicios. Ponencia presentada en el First International Forum on Translation/Interpreting and Social Activism. Recuperado de http://www.translationactivism.com/articles/Raquel_Lazaro.pdf (última consulta: 7 de abril de 2017)

López Noguero, F. (2007) Metodología participativa en el aula universitaria. Narcea S.A. de Ediciones, Madrid

Martin, A. (2015) La formación en interpretación en España: pasado y presente. MonTI. Monografías de Traducción e Interpretación, núm. Esp. 2, pp. 87-110. doi: http://dx.doi.org/10.6035/MonTI.2015.ne2.3

Martín, X. (1992) El role-playing. Una técnica para facilitar la empatía y la perspectiva social. Comunicación, Lenguaje y Educación, 15, pp. 63-67. Recuperado de https://dialnet.unirioja.es/descarga/articulo/126264.pdf (última consulta: 7 de abril de 2017)

Mitchell, G. (1998) Role-Playing Rhetoric of Science Pedagogy and the Study of Medical Ethics. Ponencia presentada en la National Communication Association Convention, New York, NY.

Monzó Nebot, E. (2003) Las socializaciones del traductor especializado: El papel de los géneros. Revista de la Facultad de Lenguas Modernas, 6, pp. 15-29.

Monzó Nebot, E. (2006) The Example of Experts in the Training of Legal Translators. Translation Ireland. New Vistas in Translator and Interpreter Training (special issue), 17(1). John Kearns. Ed. Dublin: Irish Translators' and Interpreters' Association, pp. 69-91.

PACTE. (2001) La competencia traductora y su adquisición. Quaderns. Revista de Traducció, 6, pp. 39-45. Recuperado de http://ddd.uab.cat/record/2736? In=ca (última consulta: 7 de abril de 2017)

Ruiz Mezcua, A. (2015) Aplicación práctica de la interpretación judicial a las aulas universitarias. Quaderns, Revista de Traducció, 22, pp. 307-323. Recuperado de http://ddd.uab.cat/record/132755/ (última consulta: 7 de abril de 2017)

Valero Garcés, C. (2006) Formas de Mediación Intercultural, Traducción e Interpretación en los Servicios Públicos. Conceptos, datos, situaciones y práctica. Comares, Granada.

Way, C. (2009) Bringing Professional Practices into Translation Classrooms. En: I. Kemble (Ed.), The Changing Face of Translation (pp. 131-142). University of Portsmouth, Portsmouth. 